\title{
Solution Processed AZO Thin Films Prepared from Different Source Materials
}

\author{
Sana Ullah ${ }^{1,2^{*} \dagger}$, Fabio De Matteis ${ }^{1}$, Massimiliano Lucci ${ }^{2}$, Ivan Davoli ${ }^{2}$ \\ ${ }_{1}^{1}$ Dipartimento di Ingegneria Industriale, Università degli Studi di Roma "Tor Vergata", Via del Politecnico, 1, \\ 00133, Roma, Italy \\ 2 Dipartimento di Fisica, Università degli Studi di Roma "Tor Vergata", Via della Ricerca Scientifica, 1, 00133, \\ Roma, Italy \\ ${ }^{3}$ Department of Basic Sciences \& Humanities, Khawaja Fareed University of Engineering \& Information \\ Technology, Abu Dhabi Road, Rahim Yar Khan, Pakistan
}

(Received 21 January 2017; published online 15 July 2013)

\begin{abstract}
Aluminum doped Zinc Oxide films were spin-coated from $1 \mathrm{~mol} \%$ doped precursors obtained from different source materials optimizing post-deposition annealing in controlled atmospheres. AZO films were provided with pre-deposition heating at $500^{\circ} \mathrm{C}$ in ambient while post-deposition rapid thermal annealing (RTA) in vacuum and in $\mathrm{N}_{2}-5 \% \mathrm{H}_{2}$ was provided at 400,500 and $600{ }^{\circ} \mathrm{C}$. Dominant $\mathrm{ZnO}$ c-axis oriented AZO films with typical wurtzite crystal structure were obtained. Aluminum nitrate source materials resulted in comparatively higher conductivity AZO films. We conclude post-deposition annealing in controlled environments helped increase oxygen vacancies and enhanced grain growth and crystallinity resulting in increased conductivity. Optical measurements showed an average total transmittance (\%T) of about $85 \%$ in the visible for all the films with a direct allowed band gap of about 3.2.
\end{abstract}

Keywords: AZO, Solution synthesis, Spin coating, Rapid thermal annealing, Transparent conducting oxides.

DOI:

PACS number(s): 81.15.-z, 67.60.gj

\section{INTRODUCTION}

Transparent metal oxides and thin conducting films are an integral part of nowadays display and touch- 66 screen applications. Indium Tin Oxide (ITO), thanks to 67 its low resistivity, high optical transparency and chem- 68 ical stability, holds stronger the transparent conduct- 69 ing oxide (TCO) market. The increasing industry de-70 mands, coupled with scarce indium element resources, 71 compel to look for alternatives. Zinc oxide $(\mathrm{ZnO})$ has 72 been looked at as an alternative and is being investi- 73 gated by researched community [1]. $\mathrm{ZnO}$, an otherwise 74 insulator in its perfect crystal form, is an n-type semi- 75 conducting compound due to non-stoichiometry of in-76 trinsic defects of oxygen vacancy and zinc interstitials. The stability of intrinsic $\mathrm{ZnO}$, along with enhanced 78 conductivity is achieved by adding elements which act 79 as donors that replace the $\mathrm{Zn}$ atoms and increase free 80 electron density, carrier concentration, or both [2].81 Even the dopants, they give stability to films at high 82 temperatures [3-4], and among different dopants, 83 $\mathrm{Al}: \mathrm{ZnO}$, is of greater interest because of the wide avail- 84 ability, for the ease of doping and for the variety of 85 preparation techniques \& processes [4-7]. In this work 86 we report on AZO thin films, prepared through solution 87 synthesis, that avoid the complexities of the vacuum 88 equipment. AZO films were prepared from precursors 89 obtained using different dopant sources for aluminum.90 A post-deposition thermal treatment, RTA, under vac-91 uum and under $\mathrm{N}_{2}-5 \% \mathrm{H}_{2}$ atmosphere for 10 minutes 92 each at 400,500 and $600{ }^{\circ} \mathrm{C}$ temperatures was provid- 93 ed. Aluminum nitrate sources along with RTA has been 94 found to be very effective in giving higher conductivity 95 with required optical transparency to films in compara-96 tively short times of application keeping the thicknesses comparatively lower.

\section{EXPERIMENTAL DETAILS}

Zinc acetate dehydrate $\left(\mathrm{Zn}\left(\mathrm{CH}_{3} \mathrm{CO}_{2}\right)_{2.2} \mathrm{H}_{2} \mathrm{O}\right.$, trace metal basis, $99.999 \%$ ) was used as a starting material with 2-methoxyethanol $\left(\mathrm{CH}_{3} \mathrm{O}\left(\mathrm{CH}_{2}\right)_{2} \mathrm{OH}\right.$, anhydrous, 99.8\%) (2-MEA) as solvent and mono-ethanolamine $\left(\left(\mathrm{HOC}_{2} \mathrm{H}_{4}\right) \mathrm{NH}_{2}\right.$, min. 99\%) (MEA) $(99 \%$ min) as stabilizer. Aluminum chloride hexahydrate (AlCl3.6H2O, anhydrous, powder, 99.999\%, trace metal basis) and aluminum nitrate nonahydrate $\left(\mathrm{AlN}_{3} \mathrm{O}_{9.9} \mathrm{H}_{2} \mathrm{O}\right.$, anhydrous, powder, $99.999 \%$, trace metal basis) in $1 \mathrm{~mol} \%$ were used as dopants. All ingredients were used as purchased from Sigma Aldrich. The starting material was dissolved in solvent, at $0.35 \mathrm{M}$ concentration, and the MEA was added in molar ratio of 1:1. Solutions were stirred at $60{ }^{\circ} \mathrm{C}$ for 2 hours to obtain clear and homogeneous solutions and were brought to room temperature and aged for 2 days. Solutions were stirred again at $60^{\circ} \mathrm{C}$ for 10 minutes and cooled to room temperature before deposition of films. Corning glass substrates were cleaned in an ultrasonic bath at $60^{\circ} \mathrm{C}$ first in acetone and then in 2-isopropanol, each for 15 minutes. After drying with $\mathrm{N}_{2}$, substrates received a 30 minutes UV/Ozone surface activation step in a PSD-UV Novascan system. Individual layers were spin coated at $3000 \mathrm{rpm}$ for 30 seconds. Successive layers received pre-deposition consolidation heating at $500^{\circ} \mathrm{C}$ for 10 minutes. Post-deposition RTA was provided in vacuum and then in $\mathrm{N}_{2}-5 \% \mathrm{H}_{2}$ environment at 400, 500, and $600{ }^{\circ} \mathrm{C}$ for 10 minutes each to whole of film stacks.

Electrical resistance of thin films was first assessed

\footnotetext{
*sanaullahzafar@yahoo.com

† sana.ullah@kfueit.edu.pk
} 
1 first by measuring the sheet resistance using four-point 56 probe method with a Jandel Engineering, UK instru-57 ment and then calculating the resistivity by the formu-58 la $\rho=V / I x t$, where " $t$ " refers to the thickness of film 59 and " $V$ " is the voltage drop across the sample at the 60 applied current " $T$ ". Hall Effect measurements were61 carried out using HL555 LN2 CRYOSTAT system by 62 Nanometrics to know in detail bulk resistivity, carrier 63 concentration and mobility. The films were character- 64 ized by optical transparency in the visible using a Per- 65 kin Elmer Lambda 950 UV/VIS/NIR Spectrophotome-66 ter. Thickness of AZO films was measured using Ambi-67 os XP-200 Profilometer. The structure of films was ob- 68 served by X-ray diffraction (XRD).

\section{RESULTS AND DISCUSSIONS}

Films intended for application as TCO are mainly ${ }_{73}$ characterized for electrical resistivity and optical 74 transparency. Increased thickness could potentially 75 result in low electrical resistivity films, but transparen- 76 cy would be then compromised. While very thin films 77 are optically transparent but have higher resistivity. 78 Here we report results for films which possess required 79 conductivity with desired optical transparency in the visible. Comparable results vis-à-vis electrical conductivity and optical transparency were achieved keeping 82 the thickness, amount of source materials, annealing 8 temperatures and annealing time comparatively lower 84 than those reported in literature for films prepared 85 through solution synthesis [8-17].

\subsection{XRD structural analysis}

$\mathrm{XRD}$ analysis was carried out in the $2 \theta$ range of $0^{\circ}$ to $80^{\circ}$ to determine physical structure and level of crystallinity of prepared films using Panalytical X'Pert PRO diffractometer in Bragg-Brentano $(\theta / 2 \theta$ coupled) geometry with $\mathrm{Cu} K_{\alpha}$ line radiation $(\lambda=1.540598 \AA$ ). 94 Fig. 1 shows diffraction peaks in case of films of both dopants. All the films irrespective of the dopant and pre- and post-deposition annealing were found strongly $c$-axis oriented with characteristic $\mathrm{ZnO}$ hexagonal wurtzite structure and diffraction peak of crystal orientation (002) appearing at about $34.5^{\circ}$ due to self $_{100}$ texturing phenomena [18].

For both the dopants, only characteristic zinc oxide diffraction peaks appeared with very much increased intensity [19] in contrast to other examples [20] where ${ }_{04}$ other peaks appeared as well. This shows that RTA

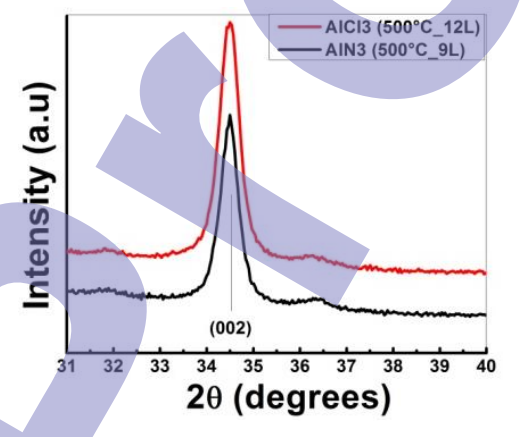

54

Fig. 1 - Diffraction peaks for the films of both dopants post-deposition depress the growth of other peaks [21] and increases the growth of the characteristic peak. Also smaller width of the peak of $\mathrm{AlN}_{3} \mathrm{O}_{9} .9 \mathrm{H}_{2} \mathrm{O}$ dopant solution in comparison to films from $\mathrm{AlCl}_{3} .6 \mathrm{H}_{2} \mathrm{O}$ dopant solution indicates increased grain growth with a monocrystalline character of these films. This tendered higher mobility to charge carriers and eventually reduced resistivity in case of $\mathrm{AlN}_{3} \mathrm{O}_{9.9} \mathrm{H}_{2} \mathrm{O}$ doped films as shown and described in sect. 3.2. We ascribe this enhanced crystallinity to the post-deposition double RTA treatment which helped enhance diffusion of dopants into the $\mathrm{ZnO}$ structure and increased densification of grains as is clear in SEM (sect. 3.4) analysis. This resulted in decreased porosity in the films and increased mobility of carriers. These factors were more prominent in case of $\mathrm{AlN}_{3} \mathrm{O}_{9.9} \mathrm{H}_{2} \mathrm{O}$ doped $\mathrm{AZO}$ films. All these factors helped to decrease resistivity of the films.

\subsection{Electrical measurements}

The electrical resistance of the films, were first checked by a commercial multi-meter, and the ones that show, reasonable value, are better characterized by four-point method. Resistivity values were then calculated multiplying the sheet resistance by thickness of the films. To complement the measurements and confirm the resistivity values, Hall Effect electrical measurements were done to know in detail the electrical behavior of the AZO films treated with RTA temperatures in different controlled environments after preparation. Table 1 presents bulk resistivity, Hall mobility and carrier concentration in case of films with $\mathrm{AlCl}_{3.6} \mathrm{H}_{2} \mathrm{O} \& \mathrm{AlN}_{3} \mathrm{O}_{9.9} \mathrm{H}_{2} \mathrm{O}$ as dopants respectively. Films were given double RTA treatment in controlled environments, first in vacuum and then in $\mathrm{N}_{2}-5 \% \mathrm{H}_{2}$. Thickness of the films from $\mathrm{AlCl} 3.6 \mathrm{H} 2 \mathrm{O}$ precursor solutions was almost double $(220 \mathrm{~nm})$ in comparison to films of $\mathrm{AlN}_{3} \mathrm{O}_{9.9} \mathrm{H}_{2} \mathrm{O}(120 \mathrm{~nm})$ precursors. This higher amount of material provided more than double the charge carrier concentration in the $\mathrm{AlCl}_{3.6} \mathrm{H}_{2} \mathrm{O}$ precursor solution films. This higher carrier concentration however hindered the growth of grains and increased grain boundary area for $\mathrm{AlCl}_{3.6} \mathrm{H}_{2} \mathrm{O}$ precursor solution films. This also increased scattering events in case of $\mathrm{AlCl}_{3.6} \mathrm{H}_{2} \mathrm{O}$ precursor solution films. Hence reduced their mobility. In comparison charge carrier concentrations remained lower for $\mathrm{AlN}_{3} \mathrm{O}_{9.9} \mathrm{H}_{2} \mathrm{O}$ precursor solution films which reduced scattering events. This is the reason mobility of the charge carriers remained double for films from $\mathrm{AlN}_{3} \mathrm{O}_{9.9} \mathrm{H}_{2} \mathrm{O}$ precursor solution. This is in confirmation with the results showed by XRD analysis in sect. 3.1. RTA treatment resulted in grain growth \& densification of the films. Comparatively bigger grains in case of AlN3O9.9H2 films resulted in reduced area of grain boundaries and hence reduced scattering. We argue that this helped increase mobility for $\mathrm{AlN}_{3} \mathrm{O}_{9.9} \mathrm{H}_{2}$ precursor solution films. This helped to achieve higher conductivity for these $\mathrm{AlCl}_{3.6} \mathrm{H}_{2} \mathrm{O}$ precursor solution films. On the other hand, carrier concentration in the range of $10^{19} \mathrm{~cm}^{-3}$ was achieved at half thickness for films of $\mathrm{AlN}_{3} \mathrm{O}_{9.9} \mathrm{H}_{2}$ dopant. This helped to reduce amount of material consumption. Films of both dopant sources however showed n-type conductivity. 
Table 1 - Resistivity, Hall mobility and carrier concentrations values for the two types of films

\begin{tabular}{|c|c|c|c|c|c|}
\hline \multicolumn{2}{|c|}{$\mathrm{AlCl}_{3.6} \mathrm{H}_{2} \mathrm{O}$ doped films $(220 \mathrm{~nm})$} & \multicolumn{2}{c|}{$\mathrm{AlN}_{3} \mathrm{O}_{9.9} \mathrm{H}_{2} \mathrm{O}$ doped films $(120 \mathrm{~nm})$} \\
\hline $\begin{array}{c}\text { Resistivity } \\
(\Omega \cdot \mathrm{cm})\end{array}$ & $\begin{array}{c}\text { Hall Mobility } \\
\left(\mathrm{cm}^{2} / \mathrm{V}-\mathrm{s}\right)\end{array}$ & $\begin{array}{c}\text { Concentration } \\
\left(\mathrm{cm}^{-3}\right)\end{array}$ & $\begin{array}{c}\text { Resistivity } \\
(\Omega \cdot \mathrm{cm})\end{array}$ & $\begin{array}{c}\text { Hall Mobility } \\
\left(\mathrm{cm}^{2} / \mathrm{V}-\mathrm{s}\right)\end{array}$ & $\begin{array}{c}\text { Concentration } \\
\left(\mathrm{cm}^{-3}\right)\end{array}$ \\
\hline $3.710^{-3}$ & 4.07 & $-9.120 \cdot 10^{19}$ & $3.02 \cdot 10^{-3}$ & 10.7 & $-4.232 \cdot 10^{19}$ \\
\hline
\end{tabular}

3

Fig.2 - Optical transmittance in case of films of both dopant solutions

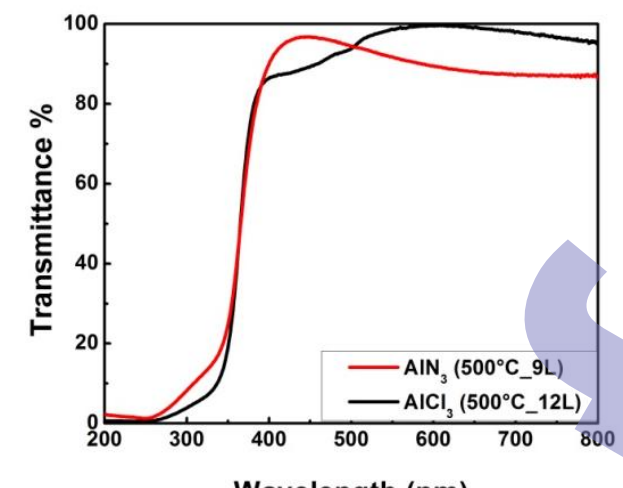

The films received similar pre- and post-deposition 36 annealing treatments in ambient and in controlled at- 38 mospheres. The stacks were developed by successive 39 single layer deposition. The films of both dopants however contained different number of layers so varied in thickness. Thickness of $\mathrm{AlCl}_{3} .6 \mathrm{H}_{2} \mathrm{O}$ films was $220 \mathrm{~nm}$ while the thickness was $120 \mathrm{~nm}$ for $\mathrm{AlN}_{3} \mathrm{O}_{9.9 \mathrm{H}_{2} \text {. Total }}$ optical transmission remained more than $80 \%$ for both films. Optical transmission obtained for both films are reported in Fig. 2. As charge carrier concentration increased, their mobility decreased as measured in electrical characterizations given in section 3.2. Higher carrier concentration with reduced mobility enhanced 4 carrier scattering events and reduced transmission

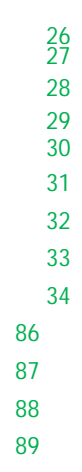

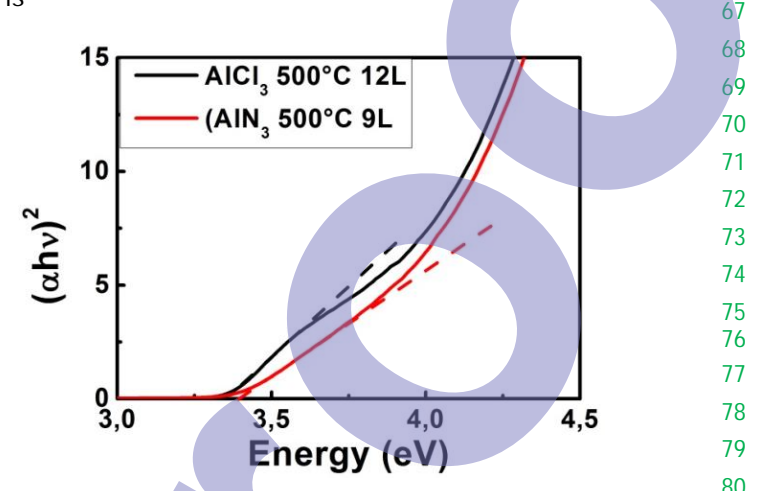

Fig. 3 - Energy band gaps as calculated from Tauc's plot for 81 films of both the dopants

whereas higher mobility with lower carrier concentration reduced scattering events and helped increase transmission. However increased grain size due to high ${ }^{85}$ annealing temperatures as observed in XRD analysis when became comparable or larger than light wavelength resulted in diffusion of light and reduced transmittance for films.

Oscillations in transmitted light are generated from interfaces by multiple reflections at the upper and lower interfaces of oxide films as a function of wavelength. The decrease in transmission at lower wavelengths is ascribed to optical band to band absorptions [22]. The absorption edge was calculated in Tauc plot as $(\alpha h v)^{2}$ vs. $h v$ for the direct allowed transition for both the films and remained a little more than $3.0 \mathrm{eV}$ which is typical value for semiconducting materials.

\section{CONCLUSION}

In this work two group of films were prepared. The films of group 1 were prepared from precursor solution with $\mathrm{AlN}_{3} \mathrm{O}_{9.9} \mathrm{H}_{2}$ as dopant and while films of group 2 were prepared from precursor solutions of $\mathrm{AlCl}_{3.6} \mathrm{H}_{2} \mathrm{O}$ as dopant. As pure $\mathrm{ZnO}$ carries oxygen vacancies and zinc interstitials as charge carriers, more of the carriers generated in case of $\mathrm{AlCl}_{3.6} \mathrm{H}_{2} \mathrm{O}$ dopant. However, mobility was more than double in case of $\mathrm{AlN}_{3} \mathrm{O}_{9.9} \mathrm{H}_{2}$ films. Use of $\mathrm{AlN}_{3} \mathrm{O}_{9.9} \mathrm{H}_{2}$ source material proved advantageous providing better conducting films at lower thicknesses reducing use of precursor materials. Rapid thermal annealing proved its efficacy in enhancing densification of films and increasing grain sizes hence reduction in resistivity. The spread out of heat in furnace tube lowers the effectiveness of the heating method. This is the reason that in case of furnace tube, longer times of annealing are normally required. RTA on the other hand, with its "direct" heating helps lower the time of application. Controlled atmospheres in the case of RTA also reduce possibility of contamination which adds to its usefulness to obtain compact thin films with high transparency \& low resistivity. Better conductivity and transparent films were obtained with application of RTA for lower times of application.

\section{AKNOWLEDGEMENTS}

Author Sana Ullah would like to express his gratitude for Prof. Dr. Elvira Fortunato for providing an opportunity to work at Centre for Materials Research (CENIMAT/I3N), New University of Lisbon, Caparica, Portugal under EU ERASMUS placement. Sana Ullah also acknowledges $\mathrm{PhD}$. Joana Pinto for XRD analysis, M.Sc Alexandra Goncalves for guidance in UV/VIS/IR Spectroscopy analysis and PhD Daniela Gomes for SEM surface analysis at CENIMAT/I3N. 


\section{REFERENCES}

1. Ümit Özgür, Daniel Hofstetter, Hadis Morkoc, Proceedings 30 of the IEEE 98 No 7, 1255 (2010).

2. S.J. Pearton, D.P. Norton, K. Ip, Y.W. Heo, T. Steiner, 32 Superlatt. Microstr. 34, 3 (2003).

3. Tadatsugu Minami, Hirotoshi Sato, Hidehito Nanto, 34 Shinzo Takata, Jpn. J. Appl. Phys. 24 L781 (1985).

4. Hyung Jun Cho, Sung Uk Lee, Byungyou Hong, Yong 36 Deok Shin, Jin Young Ju, Hee Dong Kim, Mungi Park, 37 Won Seok Choi, Thin Solid Films 518, 2941 (2010).

5. Yung-Chen Cheng, Appl. Surf. Sc. 258, 604 (2011).

6. Deok-Kyu Kim, Hong Bae Kim, Current Appl. Phys. 13, 40 2001 (2013).

7. S. Ullah, F. De Matteis, R. Branquinho, E. Fortunato, 42 R. Martins, I. Davoli, IEEE-NANO 2015 - 15th Interna- 43 tional Conference on Nanotechnology 7388919, 144 (2016). 44

8. E.J. Luna-Arredondo, A. Maldonado, R. Asomoza, 45 D.R. Acosta, M.A. Mele'ndez-Lira, M. de la L. Olvera, 46 Thin Solid Films 490, 132 (2005).

9. Seung-Yup Lee, Byung-Ok Park, Thin Solid Films 484, 48 184 (2005).

10. Min-Chul Jun, Jung-Hyuk Koh, J. Electrical Eng. Technol. 50 8 No 1,163 (2013).

11. Shou-Yi Kuo, Wei-Chun Chen, Fang-I Lai, Chin-Pao 52 Cheng, Hao-Chung Kuo, Shing-Chung Wang, Wen-Feng Hsieh, J. Crystal Growth 287, 78 (2006).

12. Jin-Hong Lee, Byung-Ok Park, Thin Solid Films 426, 94
(2003).

13. Jun, Min-Chul; Koh, Jung-Hyuk, J. Nanosci. Nanotech. 13 No 5, 3403 (2013).

14. Vrushali Shelke, M.P. Bhole, D.S. Patil, Mater. Chem. Phys. 141, 81 (2013).

15. Hao Tong, Zhonghua Deng, Zhuguang Liu, Changgang Huang, Jiquan Huang, Hai Lan, Chong Wang, Yongge Cao, Appl. Surf. Sci. 257, 4906 (2011).

16. S. Major, A. Banerjee, K.L. Chopra, Thin Solid Films 122 No 1,31 (1984).

17. H. Deng, J.J. Russell, R.N. Lamb, B. Jiang, Y. Li, X.Y. Zhou, Thin Solid Films 458, 43 (2004).

18. Shou-Yi Kuo, Wei-Chun Chen, Fang-I Lai, Chin-Pao Cheng, Hao-Chung Kuo, Shing-Chung Wang, en-Feng Hsieh, J. Crystal Growth 287, 78 (2006).

19. Keh-moh Lin, Paijay Tsai, Thin Solid Films 515, 8601 (2007).

20. Chi-ming Lai, Keh-moh Lin, Stella Rosmaidah, J. Sol-Gel Sci. Technol. 61, 249 (2012).

21. Min-Chul Jun, Jung-Hyuk Koh, J. Electrical Engineer. Technol. 8 No 1, 163 (2013).

22. K.W. Liu, M. Sakurai, M. Aono, J. Appl. Phys. 108, 043516 (2010).

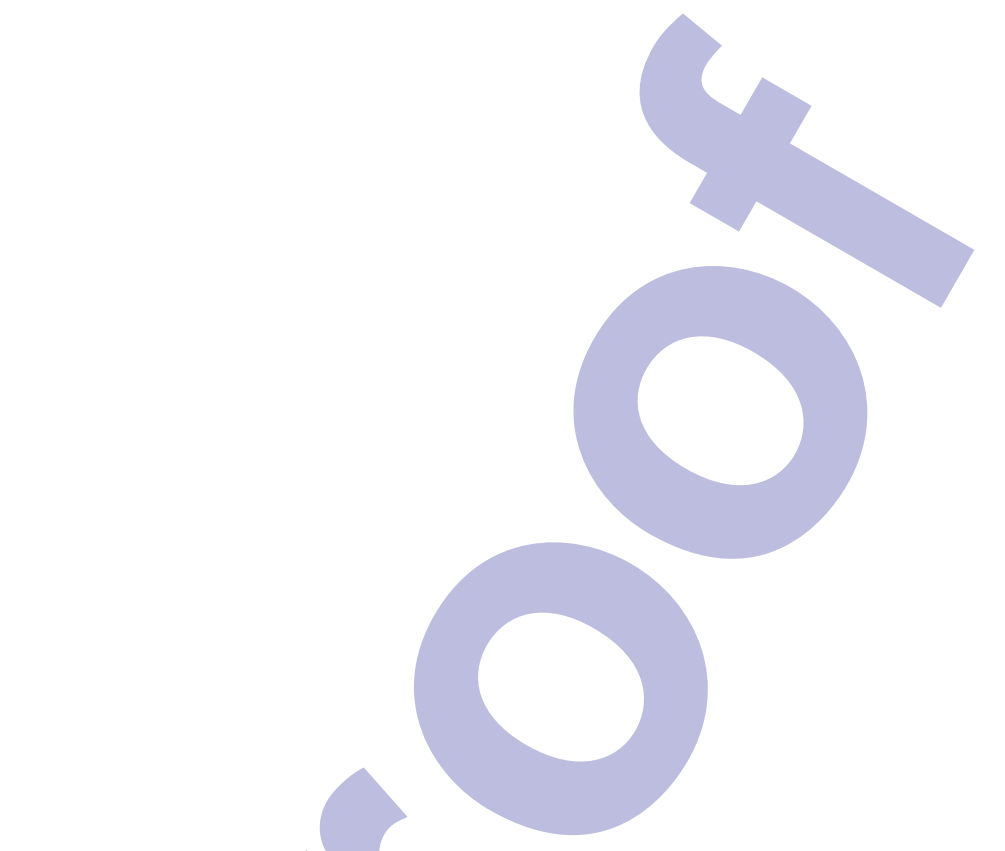

